\title{
c-myc Antisense Oligonucleotides Inhibit the Colony-forming Capacity of Colo 320 Colonic Carcinoma Cells
}

Judith F. Collins, Peter Herman, Christine Schuch, and Grover C. Bagby, Jr. Department of Medicine, Portland Veterans Administration Medical Center

and Oregon Health Sciences University, Portland, Oregon 97201

\begin{abstract}
Colo 320 cells are colonic carcinoma cells known to express abundant c-myc mRNA. Based on the response of several hematopoietic cell lines to chemical inducers of differentiation, we reasoned that such agents might have similar inductive activity in Colo 320 cells. Accordingly, we exposed Colo 320 cells to 5 mM sodium butyrate ( $\mathrm{NaBT}$ ) for $7 \mathrm{~d}$. C-myc expression decreased threefold and self-replicative potential decreased (defined as a $>60 \%$ decrease in colony-forming capacity in soft agar that did not contain inducer). In an effort to demonstrate a direct cause and effect between myc expression and the colonyforming capacity of Colo 320 cells, we exposed these cells to a 15-base antisense c-myc oligonucleotide (complementary to the translation initiation region of exon II). Cells were also exposed to equimolar $(20 \mu \mathrm{M})$ amounts of sense and missense oligonucleotides. Subsequently, cells were incubated at 10, 20,30, and $40 \mu \mathrm{M}$ antisense DNA for $16 \mathrm{~h}$, then washed and plated in oligonucleotide-free agar medium. We demonstrated that: (a) the oligomers were stable in the extracellular medium and in the cell cytoplasm; $(b)$ the uptake of the oligonucleotides was $0.7 \%$; $(c)$ sense and missense oligonucleotides had no effect on colony-forming capacity; and $(d)$ the antisense c-myc oligonucleotide resulted in a $\mathbf{4 0 - 7 5 \%}$ concentration-dependent decrease in colony-forming capacity. The specific inhibition of colony-forming capacity by antisense DNA suggests that the role of myc expression in Colo 320 cells is similar to its role in hematopoiesis, and that the failure to inhibit myc expression maintains colony-forming capacity. This system provides a new strategy for inducing differentiation and may provide further insight into the genetic factors that govern the process of colonic carcinogenesis. (J. Clin. Invest. 1992. 89:1523-1527.) Key words: colonic neoplasms • cell differentiation • oncogenes • myc $\bullet$ antisense
\end{abstract}

\section{Introduction}

The c- $m y c$ gene is highly expressed in proliferating, undifferentiated cells, and encodes for a nuclear phosphoprotein that is thought to participate in functions that control cell proliferation and differentiation. The myc proteins have been more

This work presented in part in May, 1990, at the American Federation for Clinical Research, Washington, D.C.

Address correspondence and reprint requests to Dr. Judith F. Collins, Department of Medicine (111-A GI), Portland Veterans Administration Medical Center, 3710 SW US Veterans Hospital Road, Portland, OR 97207.

Received for publication 6 May 1991 and in revised form 16 December 1991

The Journal of Clinical Investigation, Inc.

Volume 89, May 1992, 1523-1527 recently described as interacting with Max, a basic helix-loophelix zipper protein, and both may belong to a general class of DNA-binding transcription factors $(1,2)$. The evidence for linkage of myc expression and the undifferentiated phenotype has been demonstrated in several cell types, but has most consistently been found in cells of hematopoietic origin $(3,4)$. Gowda et al. (5) and Emilia et al. (6) demonstrated that the c-myc gene was expressed in immature normal myeloid precursor cells, but was repressed in terminally differentiated granulocytes and their immediate precursors. In addition, human acute myeloid leukemic cells that fail to differentiate in vitro also fail to suppress c-myc transcription (6). The linkage of c-myc expression with hematopoietic cellular differentiation has been formally tested in two ways. First, Dmitrovsky et al. (7) noted that murine erythroleukemia cells transfected with a highly promoted human c-myc gene no longer exhibited its normally inducible differentiation program. Secondly, Holt et al. (8) demonstrated that repression of $c-m y c$ expression using antisense $c-m y c$ oligodeoxyribonucleotides induced differentiation of HL-60 myeloid leukemic cells. Therefore, in hematopoietic cells the protein $m y c$ functions to maintain the primitive phenotype and the repression of $c-m y c$ is a necessary and sufficient step to commit certain primitive cells to differentiate.

Because most nonhematopoietic tumor cells also express $c-m y c$, we reasoned that the differentiation function of $c-m y c$ was likely a broadly applicable principle in multiple lineages (9). Accordingly, we tested the applicability of this model in Colo 320 cells, a human colonic carcinoma cell line. They were established from a primary human colonic carcinoma and were noted to secrete ACTH, PTH, and serotonin (10). Hence, these were thought to be representative of a neuroendocrine cell type, one of the three cell types found in human colonic mucosa (11). This cell type has been described in other primary colonic tumors and is often referred to as small cell carcinoma of the colon. Clinically, these tumors behave in an unusually malignant manner. Some investigators believe these neuroendocrine cells to be of neural crest origin; however, this is highly controversial, and there is a substantial body of literature that supports the uniform origin of epithelial, mucous, and endocrine cells in colonic mucosa from a common cell of origin (12-15). The Colo 320 cell line is representative of a small cell neuroendocrine colonic carcinoma. Of particular interest to our laboratory, these cells have multiple copies of c-myc and express abundant c-myc mRNA (16).

Because markers of differentiation are less well defined in these cells than in cells of the myeloid lineage, we chose to use loss of colony-forming capacity as a marker of differentiation $(17,18)$. We found that sodium butyrate, a known differentiation-inducing agent (19-21), repressed c-myc expression and stimulated differentiation. Based on subsequent experiments using antisense c-myc oligonucleotides, we report that the inhibition of c-myc expression per se was sufficient to account for a decreased colony-forming capacity. 


\section{Methods}

\section{Chemically induced differentiation}

Colo 320 cells [CCL 220.1; Amer. Type Culture Collection, Rockville, MD], have been described previously (16). Control cells for chemical differentiation were grown in RPMI 1640 (Gibco Laboratories, Grand Island, NY) with $10 \%$ heat-inactivated FCS at $37^{\circ} \mathrm{C} / 5 \% \mathrm{CO}_{2}$ for $2-7 \mathrm{~d}$. To induce differentiation, the cells were cultured in RPMI with $10 \%$ FCS with $5 \mathrm{mM}$ sodium butyrate for 2-7 d. Serially harvested cells (days 2-7) were evaluated for colony-forming capacity, other markers of differentiation, and c-myc expression.

\section{Markers of differentiation}

Colony-forming capacity. $10^{4}$ viable cells were suspended in $1 \mathrm{ml} 0.3 \%$ agar (Difco Laboratories Inc., Detroit, MI) made with RPMI supplemented with $10 \%$ FCS without sodium butyrate, and layered onto $0.6 \%$ agar in $35 \mathrm{~mm}$ plates with $2 \mathrm{~mm}^{2}$ grids. All samples were plated in quadruplicate. The number of colonies ( $>40$ cells/cluster) was estimated on days 1-16 (22). The number of colonies/plate was calculated as follows: Average number colonies/square $\times 185$ squares/plate (Average number colonies $=$ number colonies in 5 squares $/ 5$ ). The mean values of the quadruplicate determinations and their standard deviations were recorded. A significant decrease in colony-forming capacity was defined as a greater than or equal to $60 \%$ decrease in colonyforming ability in the exposed cells when compared with control cells (not exposed to chemical inducers of differentiation).

Phenotypic changes. Cytocentrifuge preparations ( $10^{5}$ cells; Shandon cytocentrifuge) were fixed in ethanol: glacial acetic acid (3:1), and stained with hematoxylin and eosin. Immunohistochemical stains for carcinoembryonic antigen (Hybritech, Inc., San Diego, CA), epithelial keratin (23), and neuron specific enolase (Boehringer-Mannheim Biochemicals, Indianapolis, IN) were performed. Alkaline phosphatase activity was measured using $p$-nitrophenyl phosphate as a substrate $(20$, 24-27).

Tumor formation in mice. Tumor formation was assessed by injecting groups of five male athymic Balb/C nu/nu mice with either lcc of sterile PBS, $10^{7}$ control Colo 320 cells, or $10^{7}$ Colo 320 cells exposed to $5 \mathrm{mM}$ sodium butyrate for $7 \mathrm{~d}$. Mice were housed under sterile conditions for $4 \mathrm{wk}$. Mice were weighed and tumors measured weekly. After $4 \mathrm{wk}$, mice were necropsied and the size of the tumors noted. Tumors were fixed in $10 \%$ formalin, and $5-\mu \mathrm{m}$ sections were evaluated using hematoxylin and eosin stains (28).

\section{Poly- $(A)^{+} R N A$ isolation-Northern blot analysis}

$2.5 \times 10^{6}$ control cells or cells cultured in medium containing RPMI with $10 \%$ FCS and $5 \mathrm{mM}$ sodium butyrate for $2-7 \mathrm{~d}$ were harvested, and poly-(A) ${ }^{+}$RNA extracted (29). Control and sodium butyratetreated cells were washed in sterile PBS and lysed $(0.2 \mathrm{M} \mathrm{NaCl}, 0.2 \mathrm{M}$ Tris- $\mathrm{Cl}, 1.5$ may $\mathrm{MgCl}_{2}$, sodium dodecyl sulphate, and proteinase $\mathrm{K}$ ). The lysates were incubated with oligo(dT)cellulose (Collaborative Research Inc., Bedford, MA), suspended in binding buffer $(0.5 \mathrm{M} \mathrm{NaCl}$, $10 \mathrm{mM}$ Tris-Cl), and eluted with elution buffer (10 mM Tris-Cl, $\mathrm{pH}$ 7.5). $5 \mu \mathrm{g}$ of poly-(A)+ RNA derived from control cells and from cells exposed to $5 \mathrm{mM}$ sodium butyrate for 2-7 d were subjected to electrophoresis in $1.0 \%$ agarose denaturing gels and transferred to nitrocellulose membranes (30). Filters were prehybridized and then hybridized with ${ }^{32} \mathrm{P}$-labeled DNA $\left(10^{6} \mathrm{cpm} / \mathrm{ml}\right)$ overnight at $42^{\circ} \mathrm{C}$ in hybridization buffer ( $50 \%$ formamide/Denhardt's/salmon sperm DNA). Filters were then washed in $2 \times$ standard saline citrate SSC) twice, $1 \times$ SSC, 0.1 $\times$ SSC, dried, and exposed to $x$-ray film at $-70^{\circ} \mathrm{C}(31)$.

The filters were probed with a $1.5-\mathrm{kb}$ Sst c-myc fragment from pHSR-1 (8) containing exon II and reprobed with a 2.1-kb Pst1/ BamH1 fragment of human $\gamma$-actin cDNA subcloned into pGEM3 (32). Probes were radiolabeled using Oligolabeling kit (Pharmacia LKB Biotechnology, Inc., Piscataway, NJ) and $\left.{ }^{32} \mathrm{P}\right] \mathrm{dCTP}($ sp act $3,000 \mathrm{Ci} /$ mmol; New England Nuclear, Boston, MA) to a sp act of $2 \times 10^{8}$ $\mathrm{cpm} / \mu \mathrm{g}$ DNA.
Autoradiography was performed and $m y c$ and actin transcripts evaluated by densitometric scanning. A quantitative estimate of $m y c$ and actin expression was determined by comparing densitometric values.

\section{Oligonucleotide-induced differentiation}

Antisense, sense, and missense c-myc oligonucleotides were obtained from the Midland Certified Reagent Co., Midland, TX. These 15-base deoxynucleotides have been described previously (8). The antisense oligonucleotide was complementary to the translation initiation region of the c-myc gene located at the beginning of exon II. To insure that the missense oligonucleotide ( 12 mismatched $\mathrm{bp}$ ) did not inadvertently anneal to a known sequence, the European Molecular Biology Library (IntelliGenetics, Mountain View, CA) was searched for homologous sequences (allowing up to three mismatched base pairs). The missense oligonucleotide was complementary only to a few reading frames of HTLV-1 and a portion of the neural cell adhesion molecule, NCAM. Each oligomer was labeled using T4 polynucleotide kinase (Boehringer-Mannheim Biochemicals) and $\alpha-\left[{ }^{32} \mathrm{P}\right] \mathrm{ATP}$ (sp act 6,000 $\mathrm{Ci} / \mathrm{mM}$; New England Nuclear). Cell suspensions were evaluated for stability and uptake of the oligonucleotide, as previously described (8, 33), and the resulting effect on colony-forming capacity.

Stability. To determine that the oligonucleotides were stable under experimental conditions, $5^{\prime}$ end-labeled pentadecadeoxynucleotides were incubated for $16 \mathrm{~h}$ at $37^{\circ} \mathrm{C}$ in PBS alone, in the presence of $5 \times 10^{8}$ Colo 320 cells in RPMI with $10 \%$ heat-inactivated FCS, and in medium and $10 \%$ serum alone. Aliquots from each of these fractions were ethanol precipitated and electrophoresed in a $7 \mathrm{M}$ urea, $8 \%$ polyacrylamide gel.

Cellular uptake of oligonucleotide. $5 \times 10^{5}$ Colo 320 cells in $100 \mu \mathrm{l}$ RPMI with heat-inactivated FCS were exposed to $10 \mu \mathrm{M}$ of $5^{\prime}$ end-labeled oligonucleotide for $16 \mathrm{~h}$ at $37^{\circ} \mathrm{C}$. FCS was heated to $65^{\circ} \mathrm{C}$ for 30 min to inactivate DNases. The cells were washed twice and the supernatants saved (extracellular fraction). Nonidet-P40 lysis buffer was then added, and nuclei were prepared by centrifugation. This phase represented the cytoplasmic fraction. The remaining material was the nucleoplasmic fraction. All uptake experiments were performed in duplicate. The percent uptake by the cells was calculated by the number of counts in the cytoplasmic fractions/total number of counts in the cell pellet, cell wash, and culture-medium supernatant $(8,33)$. To insure that the radioactive counts in the cytoplasmic fraction was due to labeled probe rather than a labeled phosphate, ethanol-precipitated samples of the cytoplasmic fraction were electrophoresed in $7 \mathrm{M}$ urea/8\% polyacrylamide gels and autoradiographed.

Oligonucleotide exposure. $20 \mu \mathrm{M}$ of c-myc antisense, sense, or missense oligonucleotides were added to $10^{5}$ Colo 320 cells in $100 \mu \mathrm{l}$ of RPMI with heat-inactivated serum, and incubated for $16 \mathrm{~h}$ at $37^{\circ} \mathrm{C}$. Cells were washed and colony-forming capacity determined. In subsequent experiments, cells were exposed to $10,20,30$, or $40 \mu \mathrm{M}$ antisense oligonucleotide for $16 \mathrm{~h}$ at $37^{\circ} \mathrm{C}$ to demonstrate a dose-dependent decrease in colony-forming capacity. Viability of cells was demonstrated by trypan blue exclusion.

\section{Results}

Sodium butyrate inhibited c-myc mRNA accumulation and colony-forming capacity in Colo 320 cells. Myc expression began to decrease after $2 \mathrm{~d}$ exposure to sodium butyrate (see Fig. 1), and after a 5-d exposure the cells showed a significant decrease $(\geq 60 \%)$ in colony-forming capacity (see Fig. 2). Other markers of differentiation such as morphological changes, alkaline phosphatase synthesis, and immunohistochemical stains were not helpful. Tumors formed in 9 of the 10 athymic mice injected with Colo 320 cells. Tumor size and histology were similar in mice-receiving control cells and cells exposed to sodium butyrate for $7 \mathrm{~d}$. Because $\mathrm{c}-m y c$ repression preceded the significant decline in colony-forming capacity, we tested a 
A

2.4-

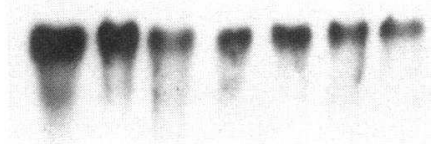

Figure 1. Myc expression in Colo 320 cells exposed to $5 \mathrm{mM}$ sodium butyrate for $0-7$ d. $5 \mu \mathrm{g}$ of poly-(A)+

B c-myc

2.0-

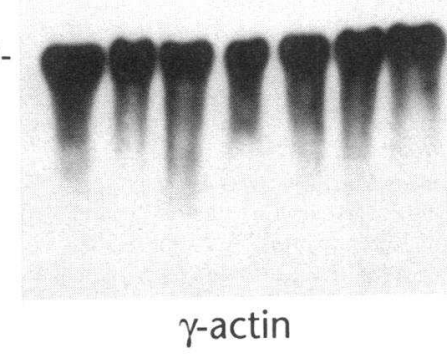

RNA were loaded into each lane and electrophoresed in a $1.0 \%$ agarose denaturing gel. The 2.4-kb myc transcript is shown in $A$ and the 2.0-kb actin transcript in $B$. A significant decrease in myc mRNA is noted in Colo 320 cells after $2 \mathrm{~d}$ exposure to sodium butyrate.

possible cause and effect relationship between c-myc expression and colony-forming capacity by using antisense methodology.

The uptake of $5^{\prime}$ end-labeled oligonucleotides (antisense, sense, and missense) by Colo 320 cells was $0.6-0.8 \%$ after $16 \mathrm{~h}$. Denaturing gel electrophoresis of the labeled oligonucleotide in the extracellular medium and in the cytoplasm of the cultured cells demonstrated that the oligonucleotide was stable for up to $16 \mathrm{~h}$ in the presence of cells (Fig. 3).

Colony-forming capacity was decreased by $50 \%$ in the antisense-exposed cells, but not in the cells exposed to sense or missense oligonucleotides (Fig. 4). Moreover, exposure to increasing doses of antisense oligonucleotide resulted in a dosedependent decrease in colony-forming capacity (Fig. 5). Cell viability was $95 \%$ in both control and antisense exposed cells when assessed by trypan blue exclusion.

\section{Discussion}

Colo 320 cells are small cell neuroendocrine colonic carcinoma cells known to actively express the c-myc protooncogene. Based on prior observations in hematopoietic cells, we pro-

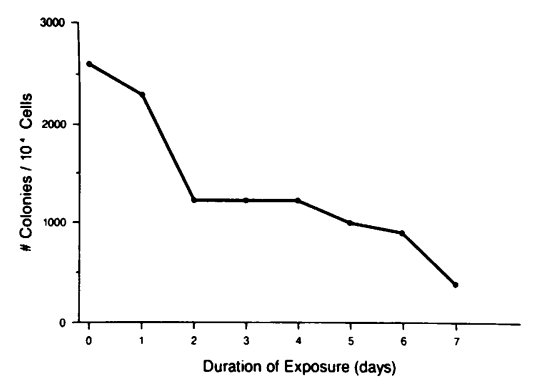

colony-forming capacity occurs after $5 \mathrm{~d}$ exposure. Each value is the mean of quadruplicate determinations.

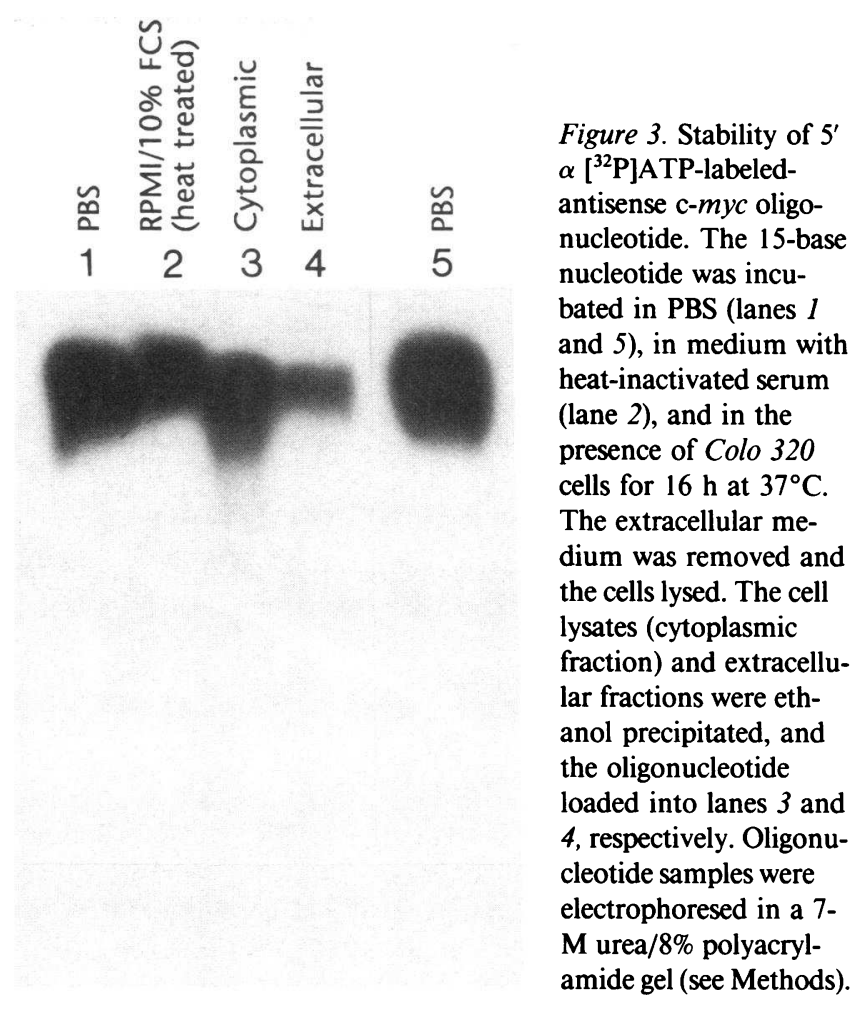

posed that $m y c$ expression was necessary to maintain the undifferentiated phenotype in these cells. Using sodium butyrate as an inducing agent, we first aimed at defining a reliable and reproducible indicator of this phenotype and the induction of a more differentiated phenotype. Light microscopic morphology, immunohistochemical stains, quantitative analyses of alkaline phosphatase synthesis, and tumor-forming ability in athymic mice and colony-forming capacity were independently assessed. Decreased colony-forming capacity was a reproducible indicator of commitment. When evaluating the cytocentrifuge preparations of induced cells, we could not reproducibly identify a change in cell morphology. Immunohistochemical stains (carcinoembryonic antigen, keratin markers [AE1, AE3], and neuron-specific enolase) were negative in both induced and uninduced cells; this is not totally unex-

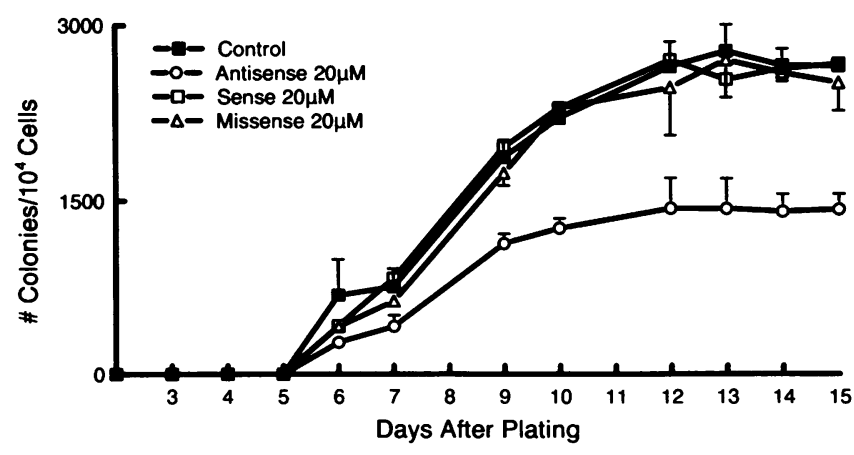

Figure 4. Colony-forming capacity of Colo 320 cells exposed to $20 \mu \mathrm{M}$ antisense, sense, or missense oligonucleotide for $16 \mathrm{~h}$ at $37^{\circ} \mathrm{C}$. Cells were washed and $10^{4}$ viable cells cultured on double-agar plates. Colonies were counted on days $1-15$. Each value is the mean \pm SD of quadruplicate determinations. 


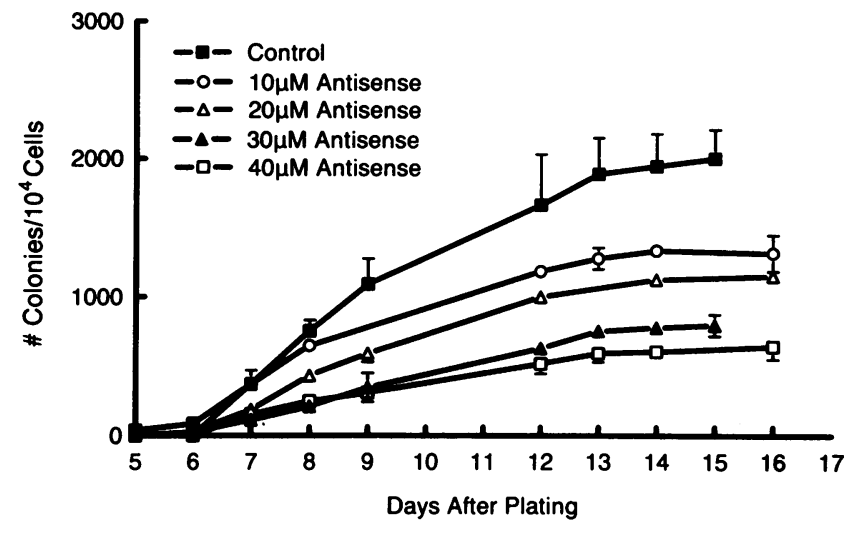

Figure 5. Colony-forming capacity of Colo 320 cells after exposure to increasing concentrations of antisense c-myc oligonucleotide for 16 $\mathrm{h}$ at $37^{\circ} \mathrm{C}$. Cells were washed and $10^{4}$ viable cells plated on doubleagar plates. Colonies were counted on days 1-16. Each value is the mean \pm SD of quadruplicate determinations.

pected in these poorly differentiated cells $(20,24)$. Alkaline phosphatase activity, a biochemical indicator used by other investigators to correlate to a particular state of differentiation in colonic carcinoma cells, actually increased after exposure to sodium butyrate (data not shown). These changes are similar to the change in activity described in other colonic carcinoma cells $(20,21,24,25)$, and were a consistent finding in our cells. However, because alkaline phosphatase activity may actually decrease in Colo 320 cells after exposure to other chemical inducers ( $2 \%$ dimethylsulfoxide; unpublished data) and in other carcinoma cells $(19,22)$, we argued that alkaline phosphatase activity was not a reliable indicator of induced differentiation.

Conceptually, an ideal biological marker of malignant cellular behavior would have been tumor-forming ability in athymic mice. The pitfall of this technique was that it required a minimum of 4 wk before quantifiable tumor growth could be assessed. During this period of time the cells were not in the presence of differentiating agents, and the fraction of cells that had not undergone commitment had time to reestablish their full colony-forming capacity. In vitro, cells exposed to and then removed from inducing agents regain their baseline colonyforming capacity within $14 \mathrm{~d}$ after removal of the agent (20). Hence, we were unable to detect differences in tumor histology, size, or metastases between animals receiving control cells and those receiving cells exposed to sodium butyrate for $7 \mathrm{~d}$. We concluded that the loss of colony-forming capacity was the most sensitive and quantitative measure of an induced commitment towards differentiation. The fact that c-myc repression preceded the decline in colony-forming capacity was compatible with the notion that the decrease in myc transcription was the cause, and not the result, of the decreased colony-forming capacity.

To formally demonstrate a direct cause and effect relationship between c-myc repression and inhibition of colony-forming capacity, we utilized an antisense oligodeoxynucleotide method. We demonstrated that the c-myc antisense and control oligonucleotides were stable in the presence of Colo 320 cells and took up the oligonucleotide intact. We noted a dosedependent decrease in colony-forming capacity after cells were exposed to antisense oligonucleotide. The lack of effect by equimolar amounts of sense or missense 15-base nucleotides on colony-forming capacity implies a specific inhibition by $m y c$ antisense. This supports the conclusion that myc expression is required to maintain colony-forming capacity and its repression is sufficient to inhibit it.

These data strongly suggest that the role of c-myc in Colo 320 cell differentiation is similar to its role in hematopoiesis, and that unrepressed myc expression maintains this colonyforming capacity and represents a primitive cell phenotype. Future studies designed to clarify the molecular determinants of $c-m y c$ repression in normal colonic epithelial cells may yield important information about one of the fundamental molecular defects in colorectal carcinoma cells.

\section{References}

1. Cole, M. D. 1986. The myc oncogene: Its role in transformation and differentiation. Annu. Rev. Genet. 20:361-384.

2. Cole, M. D. 1991. Myc meets its Max. Cell. 65:715-716.

3. Collins, S. J. 1987. The HL-60 promyelocytic leukemia cell line: proliferation, differentiation, and cellular oncogene expression. Blood. 70:1233-1244.

4. Filmus, J., and R. N. Buick. 1985. Relationship of c-myc expression to differentiation and proliferation of HL-60 cells. Cancer Res. 45:822-825.

5. Gowda, S. D., R. D. Koler, and G. C. Bagby, Jr. 1986. Regulation of c-myc expression during growth and differentiation of normal and leukemic human myeloid progenitor cells. J. Clin. Invest. 77:271-278.

6. Emilia, G., A. Donelli, S. Ferrari, U. Torelli, L. Salleri, P. Zucchini, L. Moretti, D. Venturelli, G. Ceccherelli, and G. Torelli. 1986. Cellular levels of mRNA from c-myc, c-myb and c-fes oncogenes in normal myeloid and erythroid precursors of human bone marrow: an in situ hybridization study. $\mathrm{Br}$. J. Haematol. 62:287-292.

7. Dmitrovsky, E., W. M. Kuehl, G. F. Hollis, I. R. Kirsch, T. P. Bender, and S. Segal. 1986. Expression of a transfected human c-myc oncogene inhibits differentiation of a mouse erythroleukemia cell line. Nature (Lond.). 322:748-750.

8. Holt, J. T., R. L. Redner, and A. W. Nienhuis. 1988. An oligomer complementary to c-myc mRNA inhibits proliferation of HL-60 promyelocytic cells and induces differentiation. Mol. Cell. Biol. 8:963-973.

9. Mulder, K. M., and M. G. Brittain. 1988. Alterations in c-myc expression in relation to maturational status of human colon carcinoma cells. Int. J. Cancer. 42:64-70.

10. Quinn, L. A., G. E. Moore, R. T. Morgan, and L. K. Woods. 1979. Cell lines from human colon carcinoma with unusual cell products, double minutes, and homogeneously staining regions. Cancer Res. 39:4914-4924.

11. Kirkland, S. C. 1988. Clonal origin of columnar, mucous, and endocrine cell lineages in human colorectal epithelium. Cancer (Phila.) 61:1359-1363.

12. Wick, M. R., R. P. Weatherby, and L. H. Weiland. 1987. Small cell neuroendocrine carcinoma of the colon and rectum: clinical, histologic, and ultrastructural study and immunohistochemical comparison with cloacogenic carcinoma. Hum. Pathol. 18:9-21.

13. Sarsfield, P., and P. P. Anthony. 1990. Small cell undifferentiated ('neuroendocrine') carcinoma of the colon. Histopathology (Oxf.). 16:357-363.

14. Mills, S. E., M. S. Allen, and A. R. Cohen. 1983. Small cell undifferentiated carcinoma of the colon. A clinicopathological study of five cases and their association with colonic adenomas. Am. J. Surg. Pathol. 7:643-51.

15. Petrelli, M., E. Tetangco, and J. D. Reid. 1981. Carcinoma of the colon with undifferentiated, carcinoid, and squamous cell features. Am. J. Clin. Pathol. 75:581-584.

16. Alitalo, K., M. Schwab, C. C. Lin, H. E. Varmus, and J. M. Bishop. 1983. Homogeneously staining chromosomal regions contain amplified copies of an abundantly expressed cellular oncogene (c-myc) in malignant neuroendocrine cells from a human colon carcinoma. Proc. Natl. Acad. Sci. USA. 80:1707-1711.

17. Lachman, H. M., G. Cheng, and A. T. Skoultchi. 1986. Transfection of mouse erythroleukemia cells with $m y c$ sequences changes the rate of induced commitment to differentiate. Proc. Natl. Acad. Sci. USA. 83:6480-6484.

18. Housman, D., J. Gusella, R. Geller, R. Levenson, and S. Weil. 1978. Differentiation of murine erythroleukemia cells: the central role of the commitment event. In Differentiation of normal and neoplastic hematopoietic cells. Vol. 5. Book A. B. Clarkson, P. A. Marks, and J. E. Till, editors. Cold Spring Harbor Laboratory, Cold Spring Harbor, NY. 193-207.

19. Dexter, D. L., and J. C. Hager. 1980. Maturation-induction of tumor cells using a human colon carcinoma model. Cancer (Phila.). 45:1178-1184.

20. Kim, Y. S., D. Tsao, B. Siddiqui, J. S. Whitehead, P. Arnstein, J. Bennett, and J. Hicks. 1980. Effects of sodium butyrate and dimethylsulfoxide on biochemical properties of human colon cancer cells. Cancer (Phila.). 45:1185-1192.

21. Gum, J. R., W. C. Kam, J. C. Byrd, J. W. Hicks, W. M. Sleisenger, and 
Y. S. Kim. 1987. Effects of sodium butyrate on human colonic adenocarcinoma cells. J. Biol. Chem. 262:1092-1097.

22. Buick, R. N., S. E. Fry, and S. E. Salmon. 1980. Application of in vitro soft agar techniques for growth of tumor cells to the study of colon cancer. Cancer (Phila.). 45:1238-1242.

23. Cooper, D., A. Schermer, and T. Sun. 1985. Classification of human epithelia and their neoplasms using monoclonal antibodies to keratins: strategies, applications, and limitations. Lab. Invest. 52:243-256.

24. Tsao, D., A. Morita, A. Bella, P. Luu, and Y. S. Kim. 1982. Differential effects of sodium butyrate, dimethyl sulfoxide and retinoic acid on membrane-associated antigen, enzymes, and glycoproteins of human rectal adenocarcinoma cells. Cancer Res. 42:1052-1058.

25. Morita, A., D. Tsao, and Y. S. Kim. 1982. Effect of sodium butyrate on alkaline phosphatase in HRT-18, a human rectal cancer cell line. Cancer Res. 42:4540-4545.

26. Herz, F., and H. M. Nitowsky. 1962. Alkaline phosphatase activity of human cell cultures: kinetic and physical-chemical properties. Arch. Biochem. Biophysics. 96:505-515.

27. Luk, G. D., T. K. Desai, C. N. Conteas, J. A. Moshier, and A. L. Silverman. 1988. Biochemical markers in colorectal cancer: diagnostic and therapeutic implications. Gastroenterol. Clin. of North Am. 17:931-940.
28. Povlsen, C., J. Rygaard, and J. Fogh. 1982. Long-term growth of human tumors in nude mice: evaluation of stability in the nude mouse in experimenta and clinical research. In The Nude Mouse in Experimental and Clinical Research. Vol. 2. J. Fogh, and B. C. Giovanella, editors. Academic Press, New York 79-93.

29. Badley, J. E., G. A. Bishop, T. St. John, and J. A. Frelinger. 1988. A simple, rapid method for the purification of poly $A^{+}$RNA. Biotechniques. 6:114116.

30. Thomas, P. 1980. Hybridization of denatured RNA and small DNA fragments transferred to nitrocellulose. Proc. Natl. Acad. Sci. USA. 77:5201-5205.

31. Davis, L. G., M. D. Dibner, and J. F. Battey. 1986. Basic Methods in Molecular Biology. Elsevier, New York. 143-146.

32. Gunning, P., P. Ponte, H. Okayama, J. Engel, H. Blau, and L. Kedes. 1983. Isolation and characterization of full-length cDNA clones for human $\alpha-, \beta$ and $\gamma$-actin mRNA's: skeletal but not cytoplasmic actins have an amino-terminal cysteine that is subsequently removed. Mol. Cell. Biol. 3:787-795.

33. Wickstrom, E. L., T. A. Bacon, A. Gonzalez, D. L. Freeman, G. H Lyman, and E. Wickstrom. 1988. Human promyelocytic leukemia HL-60 cell proliferation and c-myc protein expression are inhibited by an antisense pentadecadeoxynucleotide targeted against c-myc mRNA. Proc. Natl. Acad. Sci. USA. 85:1028-1032. 